\title{
Development of Temporal Rainfall Pattern for Southern Region of Sarawak
}

\author{
Rosmina A. Bustami, Nor Azalina Rosli, Jethro Henry Adam and Kuan Pei Li
}

\begin{abstract}
In the process of a design rainfall, information on rainfall duration, average rainfall intensity and temporal rainfall pattern is important. This study focuses on developing a temporal rainfall pattern for the Southern region of Sarawak since temporal pattern for Sarawak is yet to be available in the Malaysian Urban Storm Water Management Manual (MSMA), which publishes temporal pattern for design storms only for Peninsular Malaysia. The recommended technique by the Australian Rainfall and Runoff (AR\&R) known as the 'Average Variability Method' and method in Hydrological Procedure No.1-1982 are used to derive design rainfall temporal pattern for the study. Rainfall data of 5 minutes interval from year 1998 to year 2006 for 7 selected rainfall stations in the selected region is obtained from Department of Irrigation and Drainage (DID). The temporal rainfall patterns developed are for 10 minutes, 15 minutes, 30 minutes, 60 minutes, 120 minutes, 180 minutes and 360 minutes duration. The results show that Southern region of Sarawak has an exclusive rainfall pattern, which is different from the pattern developed for Peninsular Malaysia.
\end{abstract}

Keywords: Temporal Rainfall Pattern, Sarawak, Malaysian Urban Storm Water Management Manual, Average Variability Method

\section{INTRODUCTION}

$\mathrm{D}$ ESIGN flood estimation is often required in engineering practice such as design of hydrologic structures, floodplain management, river ecological studies and flood insurance studies. Thus, a design rainfall is required, which will be later converted into the corresponding design streamflow event. A design rainfall event consists of elements of rainfall duration, average rainfall intensity of an Average Recurrence Interval (ARI) event and rainfall temporal pattern. A temporal rainfall pattern is used to represent the typical variation of rainfall intensities during a typical storm and gives the proportion of total rainfall over certain time interval within a given rainfall duration [1].

In Malaysia, temporal rainfall pattern for Peninsular Malaysia is available and published in Chapter 13 of Malaysian Urban Storm Water Management Manual (MSMA) [2], however, none were developed for Sabah nor Sarawak. Two temporal rainfall patterns are available, each for the West and East Coast of Peninsular Malaysia. The patterns were prepared for 6 standard durations, $0.5,3,6,12,24$ and 72 hours. Data collected to establish the patterns were sampled from nine rainfall stations located in different parts of Peninsular Malaysia, covering nine years of rainfall data from July 1970 to July 1979.

Nevertheless, [2] indicated that [3] recommended for hydrological designs in Sabah and Sarawak to follow the temporal rainfall pattern developed for East Coast of Peninsular Malaysia for preliminary study since it was claim that the climatic conditions are more comparable than West Coast of Peninsular Malaysia. Adversely, the precipitation in Peninsular Malaysia is less compared to Sabah and Sarawak. In 2011, the annual rainfall recorded for Peninsular Malaysia is $2500 \mathrm{~mm}$ while Sarawak has recorded $4000 \mathrm{~mm}$ rainfall. For this reason, there is a need to derive a set of temporal rainfall patterns which is suitable for use in Sarawak and Sabah region.

Hence, this study is initiated to develop a set of temporal rainfall pattern with data from 7 rainfall stations situated in the southern region of Sarawak and compare the results to the patterns developed for East Coast of Peninsular Malaysia.

This work was supported by Osaka Gas Foundation for International and Cultural Exchange (OGFICE) and Universiti Malaysia Sarawak.

R. A. Bustami is with the Department of Civil Engineering, Faculty of Engineering, Universiti Malaysia Sarawak, 94300 Kota Samarahan, Sarawak.(phone: +6082-583337; fax:+6082-583410; e-mail: abrosmina@ feng.unimas.my).

N. A. Rosli is with Department of Civil Engineering, Faculty of Engineering, Universiti Malaysia Sarawak, 94300 Kota Samarahan, Sarawak.( e-mail rnazalina@ feng.unimas.my).

J.H.A is with Department of Civil Engineering, Faculty of Engineering, Universiti Malaysia Sarawak, 94300 Kota Samarahan, Sarawak.( e-mail: hajethro@feng.unimas.my).

P.L. Kuan was with Department of Civil Engineering, Faculty of Engineering, Universiti Malaysia Sarawak, 94300 Kota Samarahan, Sarawak. (e-mail: student@unimas.my). 


\section{TEMPORAL RAINFALl PATTERN}

The purpose of designing rainfall temporal patterns is to represent the typical variation of rainfall intensities during a typical storm burst. It shows the temporal distribution of rainfall within the design storm which is an important factor that affects the runoff volume, magnitude and timing of the peak discharge [2]. Realistic estimates of temporal distributions are obtained by analysis of local rainfall data from recording gauge network [4]. In Malaysia, daily and annual rainfall volumes are recorded in rainfall gauges which are recorded on a daily basis. The gauges are used throughout the country alongside a small number of pluviometers. Daily rainfall records are also of longer duration than pluviometer data although both of these attributes can be used for statistical studies. Daily rainfall data is normally readily available at or close to any location of interest for urban stormwater studies [2]. The volume rainfall influences the runoff volume and can be computed into, among others, the calculation of stormwater quality.

A study on temporal pattern is important for flood estimation as well as runoff computation, and further influence the water resource management and planning. Rainfall analyses are important for the primary aspect for hydrological designs, and temporal rainfall pattern provides the general rainfall event that may happen in the proposed project site to the designers. The patterns allow standard design procedures to be adopted in flow calculation [4]. Among the methods available to develop temporal rainfall pattern are Average Variability Method, Huff Time Distributions, Triangular Hyetograph and SCS method.

An 1982 update of [3] recommends temporal patterns adopted for design storms in Peninsular Malaysia were prepared for six standard duration $(0.5,3,6,12,24$ and 72 hours). [2] recommended that patterns of duration of one hour or less to be based on [5], while the longer durations can be based on [2]. However, it was also stated that the procedure used in [5] is more comprehensive than [2]. The standard duration recommended by [5] for urban stormwater studies are as tabled in Table 1 .

Table 1 Standard Duration Recommended

\begin{tabular}{|c|c|c|}
\hline $\begin{array}{c}\text { Standard Duration } \\
\text { (minutes) }\end{array}$ & $\begin{array}{c}\text { Number of Time } \\
\text { Intervals }\end{array}$ & $\begin{array}{c}\text { Time Interval } \\
\text { (minutes) }\end{array}$ \\
\hline 10 & 2 & 5 \\
\hline 15 & 3 & 5 \\
\hline 30 & 6 & 5 \\
\hline 60 & 12 & 5 \\
\hline 120 & 8 & 15 \\
\hline 180 & 6 & 30 \\
\hline 360 & 6 & 60 \\
\hline
\end{tabular}

The most common method use on developing temporal rainfall pattern is the Average Variability Method (AVM) since the method was being used in developing temporal rainfall patterns for Peninsular Malaysia as describe in the HP No.1 (1982) and AR\&R (1987). There are variety types of method develop the temporal rainfall patterns besides the AVM. The methods are such as Huff Time Distributions, Triangular Hyetograph and SCS Rainfall-Runoff. These methods were determined by assessing the researchers' investigations on temporal rainfall patterns working in a variety of locations around the country. For this study, Average Variability Method are most suitable method to develop the Temporal Rainfall Pattern for Sarawak as it is more informatics and recommended by AR\&R (1969), as mentioned in [6] and [7].

\section{Methodology}

This study focuses on the southern part of Sarawak, thus 7 river basins were selected to represent the rainfall pattern of the area. 5-minutes rainfall data are collected from one rainfall station on automatic recording gauge of each selected river basin for 9 years from 1998 to 2006, collected from the Department of Irrigation and Drainage (DID), Sarawak and will be further analyzed to develop temporal rainfall patterns for the area. The location of selected river basins and rainfall stations with elevation are shown in Figure 1. 


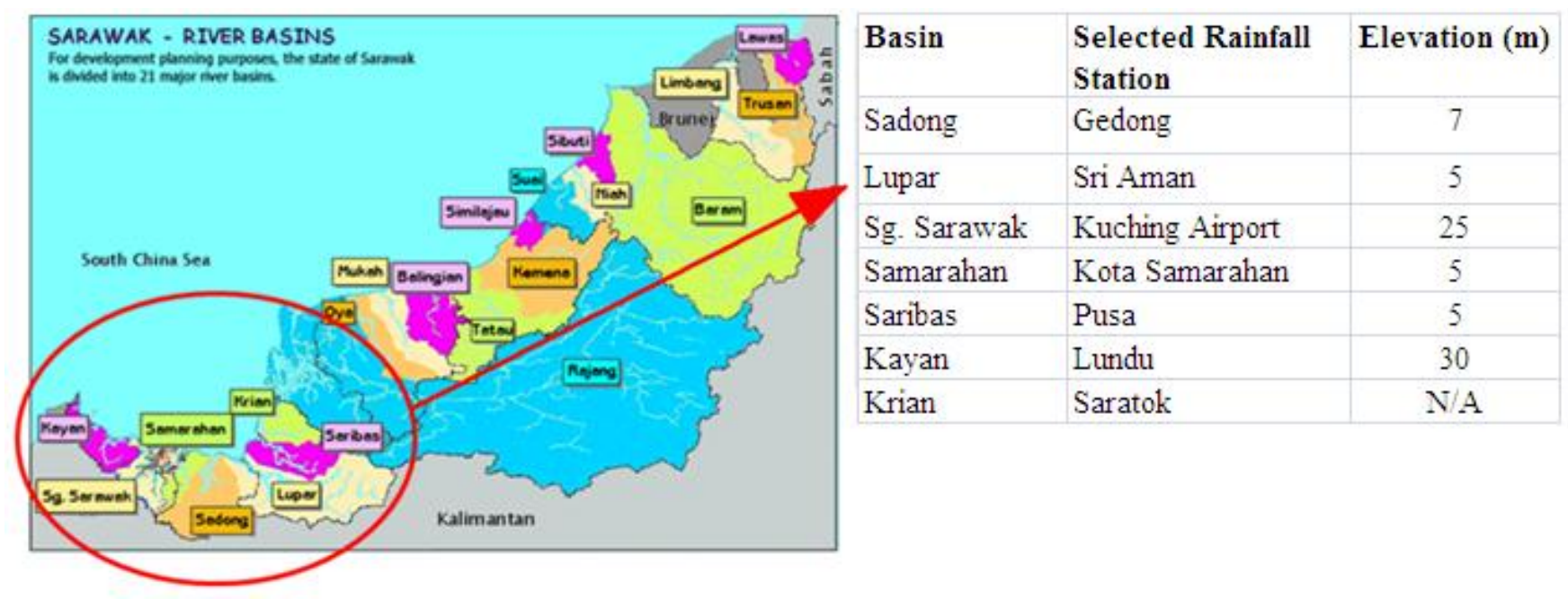

Figure 1 Location of selected river basins \& list of rainfall stations with elevation

The classification of the rainfall duration will be according to the seven standards mention by [2] which also been adopted to developed the temporal patterns for Peninsular Malaysia in [3]. The seven standard durations are 10 minutes duration, 15 minutes duration, 30 minutes duration, 60 minutes duration, 120 minutes duration, 180 minutes duration and 360 minutes duration.

The temporal rainfall pattern for each of the standard duration is developed by using Average Variability Method (AVM) following [8]. Below are the procedure taken to develop temporal rainfall patterns for Sarawak by using the AVM and recommendation by [2]:

1. From the data extraction, the 10 most intense bursts of 10 minutes, 15 minutes, 30 minutes, 60 minutes, 120 minutes, 180 minutes and 360 minutes rainfall duration were selected from the 9 water years rainfall data obtained from DID.

2. The bursts then divide into the respective time interval to give amount of rain in each rainfall period.

3. The periods then to be rank. For the same amounts of rainfall in more than one period, the average rank to be use.

4. Percentage of rain in period of each rank is then calculated and listed in order of magnitude.

5. The average value for rank of each period's rainfall is obtained and given assigned ranks base on these average values. This is for the determination of chronological order of the average heaviest period, second heaviest period and so on.

6. The average value for the percentage of rain in period of each rank is also calculated. These average percentages of rainfall are a reasonable estimate of the percentages that would occur in the periods of the burst of rainfall of average variability

7. The chronological sequence of the periods is then determined. This is by considering that the most intense rainfall within the storm should be assigned to the period whose average rank is the lowest.

Mean temporal rainfall pattern are obtain by averaging the temporal rainfall pattern for all the individual station for each group. This is to obtain one set of temporal rainfall pattern that can represent the temporal rainfall pattern for Southern region of Sarawak. The procedures are summarized in Figure 2. 


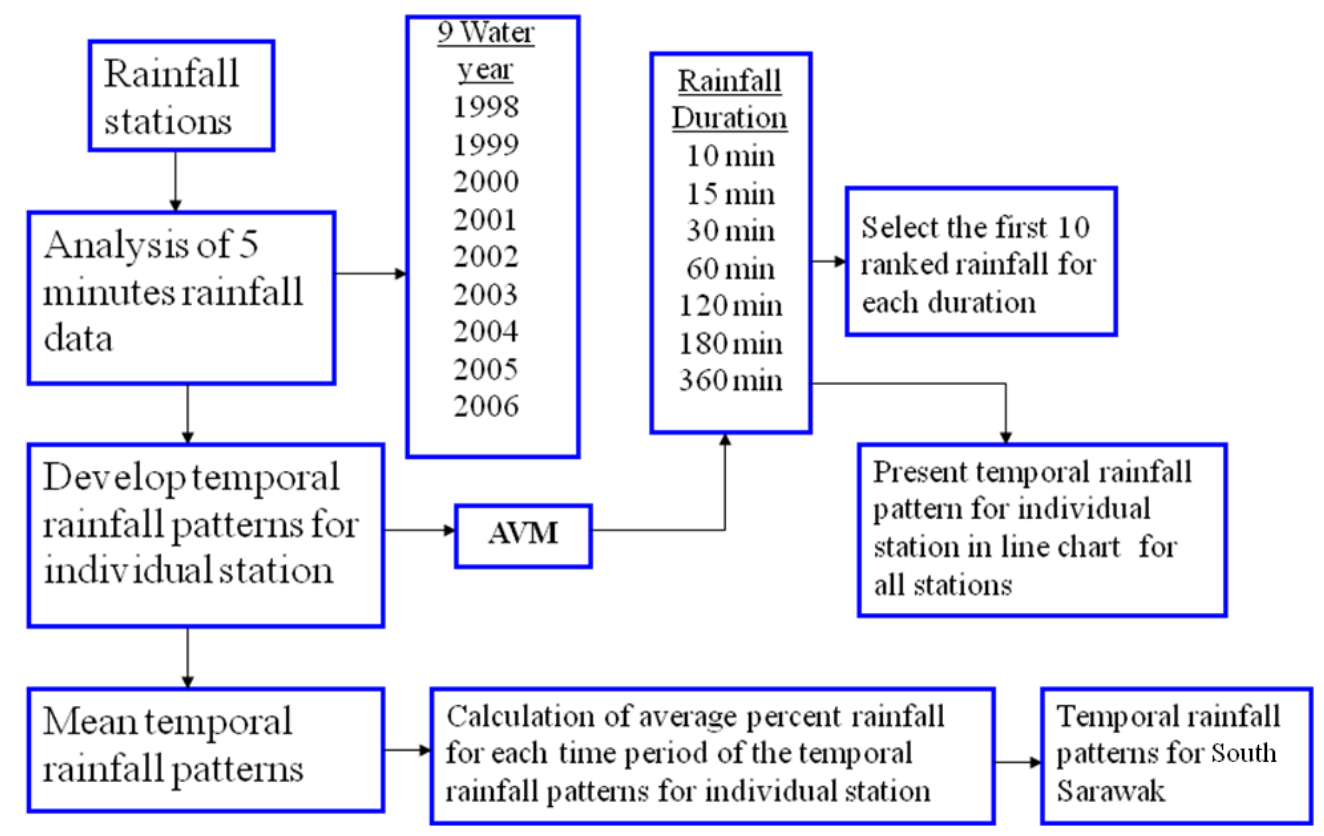

Figure 2 Methodology of Temporal Rainfall Pattern developed for this study

\section{RESULTS AND DISCUSSIONS}

A. Development of Temporal Rainfall Pattern for Southern Region of Sarawak

Analyses are made to develop individual temporal rainfall pattern for each stations before the regional temporal rainfall pattern is developed. Selection of the ten most intense rainfall for each 10 minutes, 15 minutes, 30 minutes, 60 minutes, 120 minutes, 180 minutes and 360 minutes duration are required to develop the temporal pattern based on data from $1998-2006$ for southern region of Sarawak. Each standard duration follows the ranking procedure and are divided into a set of time intervals, as shown earlier in Table 1. Derivation of temporal rainfall pattern using the Average Variability Method (AVM) sample for 15 minutes rainfall duration for Gedong rainfall station of Sadong basin is shown in Table 2.

Table 2 Analysis for 15 Minutes Rainfall Duration for Gedong station

\begin{tabular}{|c|c|c|c|c|c|c|c|c|c|c|c|}
\hline 1 & 2 & 3 & 4 & 5 & 6 & 7 & 8 & 9 & 10 & 11 & 12 \\
\hline \multirow[t]{2}{*}{ Date } & \multirow[t]{2}{*}{$\begin{array}{l}\text { Rain in } \\
\mathrm{mm}\end{array}$} & \multirow[t]{2}{*}{ Rank } & \multicolumn{3}{|c|}{ Rain in Each Period } & \multicolumn{3}{|c|}{$\begin{array}{c}\text { Rank of Each Period's } \\
\text { Rainfall }\end{array}$} & \multicolumn{3}{|c|}{$\begin{array}{c}\% \text { of Rain in Period of } \\
\text { Each Rank }\end{array}$} \\
\hline & & & 1 & 2 & 3 & 1 & 2 & 3 & 1 & 2 & 3 \\
\hline 06.11 .99 & 11.5 & 1 & 4.5 & 6.5 & 0.5 & 2 & 1 & 3 & 57 & 39 & 4 \\
\hline 28.12 .04 & 11.5 & 2 & 4.5 & 6.5 & 0.5 & 2 & 1 & 3 & 57 & 39 & 4 \\
\hline 31.12 .06 & 9.0 & 3 & 2.5 & 4.0 & 2.5 & 1.5 & 3 & 1.5 & 44 & 28 & 28 \\
\hline 11.04 .04 & 8.5 & 4 & 5.5 & 2.0 & 1.0 & 1 & 2 & 3 & 65 & 24 & 12 \\
\hline 02.02 .04 & 8.0 & 5 & 0.5 & 6.5 & 1.0 & 3 & 1 & 2 & 81 & 13 & 6 \\
\hline 16.03 .04 & 8.0 & 6 & 4.0 & 2.5 & 1.5 & 1 & 2 & 3 & 50 & 31 & 19 \\
\hline 05.11 .99 & 6.5 & 7 & 3.0 & 3.0 & 0.5 & 1.5 & 1.5 & 3 & 46 & 46 & 8 \\
\hline 29.07 .06 & 6.5 & 8 & 1.0 & 4.0 & 1.5 & 3 & 1 & 2 & 62 & 23 & 15 \\
\hline 20.10 .00 & 5.5 & 9 & 0.5 & 2.0 & 3.0 & 3 & 2 & 1 & 55 & 36 & 9 \\
\hline 02.04 .02 & 5.5 & 10 & 1.5 & 2.5 & 1.5 & 2.5 & 1 & 2.5 & 45 & 27 & 27 \\
\hline & & & \multicolumn{3}{|c|}{ Average } & 2.05 & 1.55 & 2.40 & 56 & 31 & 13 \\
\hline & & & \multicolumn{3}{|c|}{ Assigned Rank } & 2 & 1 & 3 & & & \\
\hline & & & \multicolumn{3}{|c|}{ Period } & 1 & 2 & 3 & & & \\
\hline & & & \multicolumn{3}{|c|}{$\begin{array}{l}\text { Final Pattern (\% of } \\
\text { Total Rainfall) }\end{array}$} & 31 & 56 & 13 & & & \\
\hline
\end{tabular}


The pattern of the 15-minutes rainfall burst of average variability derived from the 10 most intense 15 minutes duration bursts as shown would have 3 rainfall periods for every 5-minutes time interval containing 31\%, 56\% and $13 \%$ of the total rainfall, respectively. The analysis was produced for all 7 rainfall stations, according to the time duration. For this example, the percentages of rainfall for 15-minutes rainfall for all station are as tabulated in Table 3, while percentages of rainfall for 360 -minutes of rainfall are tabulated in Table 4

Table 3 Percentage of rainfall for a 15-minutes duration in each time period for individual station

\begin{tabular}{|c|c|c|c|c|c|c|c|}
\hline \multirow{2}{*}{$\begin{array}{c}\text { Time } \\
\text { period }\end{array}$} & \multicolumn{7}{|c|}{ \% rainfall in each time period } \\
\cline { 2 - 8 } & Gedong & Sri Aman & $\begin{array}{c}\text { Kch } \\
\text { Airport }\end{array}$ & $\begin{array}{c}\text { Kota } \\
\text { Samarahan }\end{array}$ & Pusa & Lundu & Saratok \\
\hline 1 & 31 & 35 & 20 & 32 & 35 & 17 & 16 \\
\hline 2 & 56 & 46 & 47 & 55 & 44 & 48 & 51 \\
\hline 3 & 13 & 19 & 33 & 13 & 21 & 35 & 33 \\
\hline
\end{tabular}

Table 4 Percentage of rainfall in each time period for individual station (360 minutes duration)

\begin{tabular}{|c|c|c|c|c|c|c|c|}
\hline \multirow{2}{*}{$\begin{array}{c}\text { Time } \\
\text { period }\end{array}$} & \multicolumn{7}{|c|}{ \% rainfall in each time period } \\
\cline { 2 - 7 } & Gedong & Sri Aman & $\begin{array}{c}\text { Kch } \\
\text { Airport }\end{array}$ & $\begin{array}{c}\text { Kota } \\
\text { Samarahan }\end{array}$ & Pusa & Lundu & Saratok \\
\hline 1 & 26 & 40 & 37 & 13 & 39 & 16 & 22 \\
\hline 2 & 39 & 15 & 23 & 25 & 27 & 13 & 8 \\
\hline 3 & 15 & 11 & 17 & 32 & 16 & 22 & 16 \\
\hline 4 & 10 & 20 & 10 & 16 & 9 & 33 & 24 \\
\hline 5 & 4 & 9 & 7 & 8 & 5 & 10 & 21 \\
\hline 6 & 7 & 5 & 5 & 6 & 4 & 6 & 9 \\
\hline
\end{tabular}

The analysis of 9 years rainfall data for 7 selected rainfall stations produced a total of 49 individual temporal rainfall patterns for each of the station and each time duration. An analysis done based on a study in [9] concludes that the temporal rainfall patterns can be categorized into patterns that best represents its rainfall distribution. Results of the statistical analysis for Southern Sarawak are presented in Table 5. The rainfall events for individual rainfall stations are mostly of the advanced and intermediate type pattern. More than $60 \%$ of the temporal patterns in the region are of the intermediate type.

Table 5 Temporal rainfall pattern for individual station

\begin{tabular}{|c|c|c|c|c|c|c|c|}
\hline Temporal pattern & \multicolumn{2}{|c|}{ Advanced } & \multicolumn{2}{|c|}{ Intermediate } & \multicolumn{2}{|c|}{ Delayed } & \multirow[t]{2}{*}{ Total } \\
\hline Type & $\mathrm{A}$ & $\mathrm{B}$ & $\mathrm{C}$ & $\mathrm{D}$ & $\mathrm{E}$ & $\mathrm{F}$ & \\
\hline Number of rainfall event & 16 & 0 & 23 & 3 & 0 & 0 & 42 \\
\hline Percentage of total & 38 & 0 & 55 & 7 & 0 & 0 & 100 \\
\hline Percentage by pattern & \multicolumn{2}{|c|}{38} & \multicolumn{2}{|c|}{62} & \multicolumn{2}{|c|}{0} & 100 \\
\hline
\end{tabular}

Based on the recommendations of [3], which were also practiced in [2], mean temporal rainfall pattern is adopted to obtain a set of temporal rainfall pattern from more than one rainfall station, to be applied for a larger area. The average temporal distributions are computed and temporal patterns are presented as fraction of rainfall in each time period as shown in Figure 3 . 
UNIMAS E-Journal of Civil Engineering, Vol. 3 (Special Issue) 2012

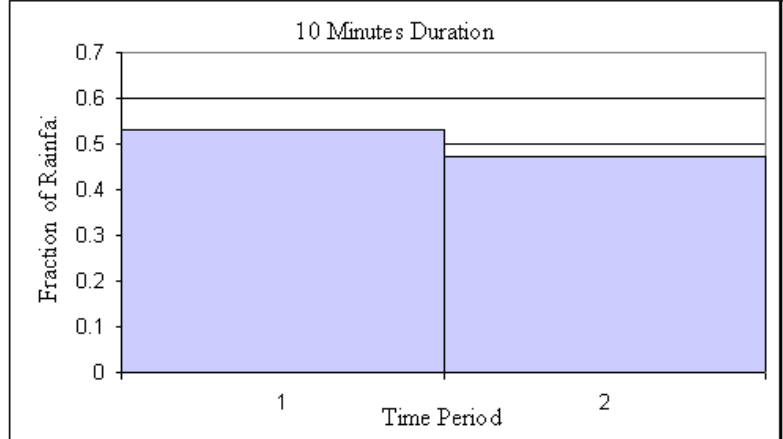

(a) Temporal rainfall pattem for 10 minutes duration

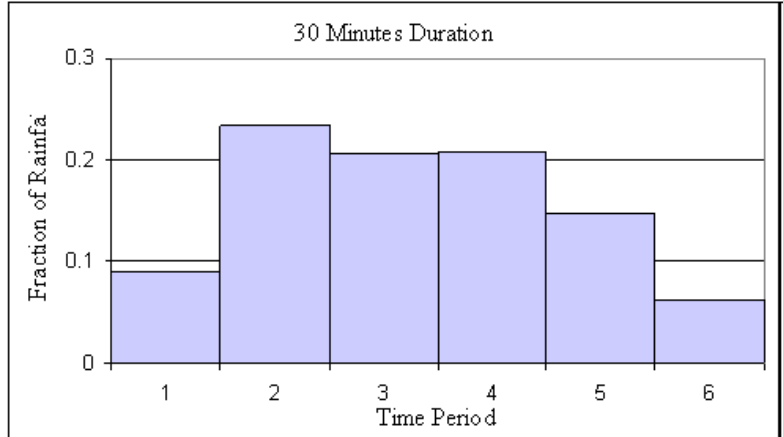

(c) Temporal rainfall pattem for 30 minutes duration

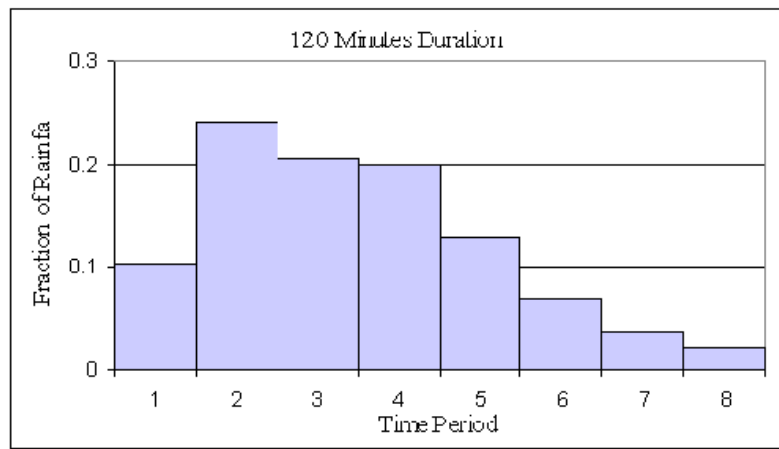

(e) Temporal rainfall pattem for 120 minutes duration

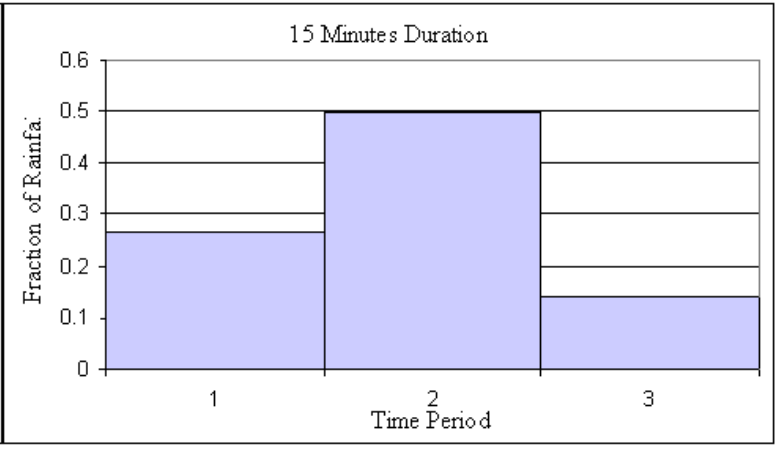

(b) Temporal rainfall pattern for 15 minutes duration

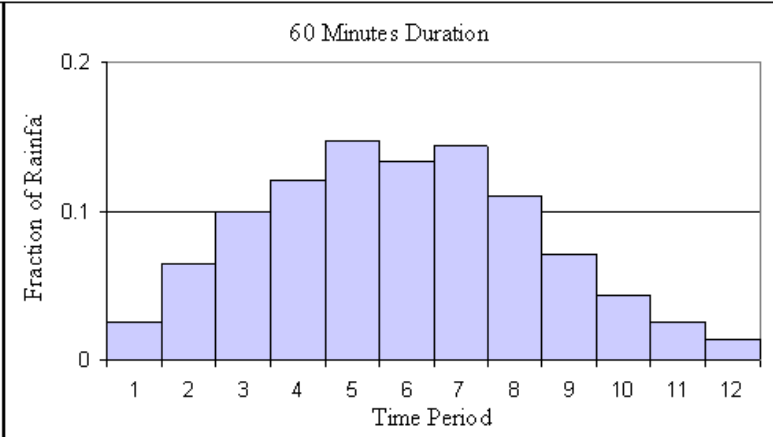

(d) Temporal rainfall pattem for 60 minutes duration

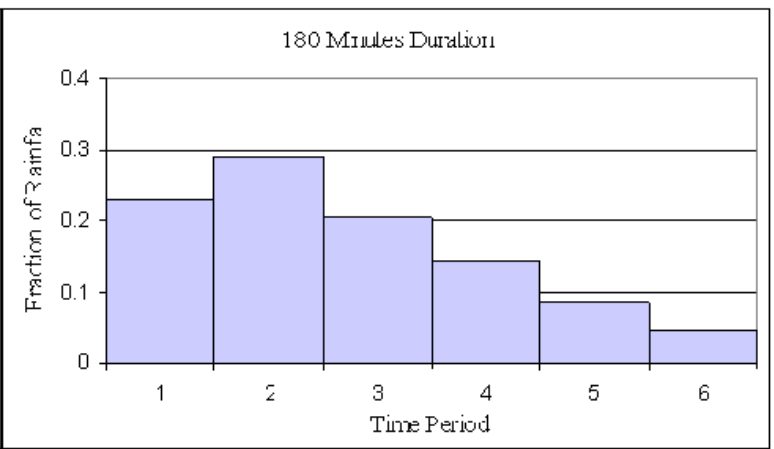

(f) Temporal rainfall pattem for 180 minutes duration

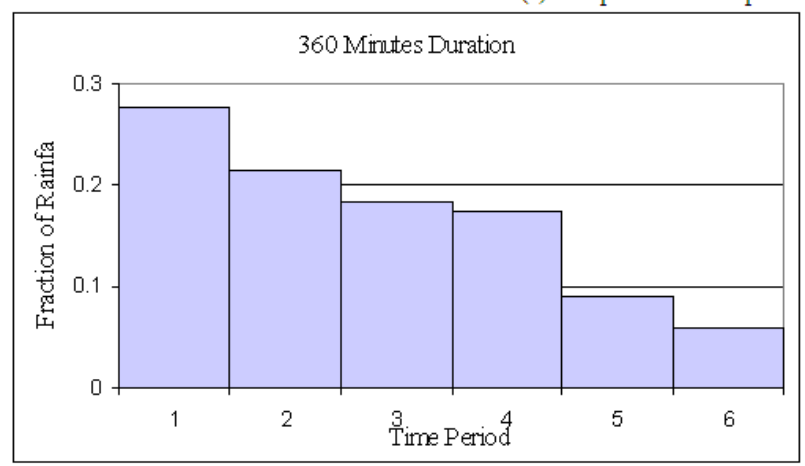

(g) Temporal rainfall pattem for 360 minutes duration

Figure 3(a) - (g) Temporal Rainfall Pattern for Southern Region of Sarawak

\section{B. Comparison of Temporal Rainfall Pattern with East Coast of Peninsular Malaysia}

A comparison is made between temporal rainfall pattern developed in this study and the one adopted for East Coast of Peninsular Malaysia, and fractions of both patterns are tabulated in Table 6. 
Table 6 Comparison of Temporal Pattern between East Coast of Peninsular Malaysia and Southern Region of Sarawak

\begin{tabular}{|c|c|c|c|c|c|c|c|c|c|c|c|c|c|}
\hline $\begin{array}{c}\text { Duration } \\
\text { (min) }\end{array}$ & $\begin{array}{l}\text { No of } \\
\text { Time }\end{array}$ & \multicolumn{12}{|c|}{ Fraction of Rainfall in Each Time Period } \\
\hline \multirow[t]{2}{*}{10} & \multirow[t]{2}{*}{2} & 0.570 & 0.430 & - & - & - & - & - & - & - & - & - & - \\
\hline & & 0.529 & 0.471 & - & - & - & - & - & - & - & - & - & - \\
\hline \multirow[t]{2}{*}{15} & \multirow[t]{2}{*}{3} & 0.320 & 0.500 & 0.180 & - & - & - & - & - & - & - & - & - \\
\hline & & 0.266 & 0.496 & 0.139 & - & - & - & - & - & - & - & - & - \\
\hline \multirow[t]{2}{*}{30} & \multirow[t]{2}{*}{6} & 0.160 & 0.250 & 0.330 & 0.090 & 0.110 & 0.060 & - & - & - & - & - & - \\
\hline & & 0.090 & 0.234 & 0.260 & 0.207 & 0.147 & 0.063 & - & - & - & - & - & - \\
\hline \multirow[t]{2}{*}{60} & \multirow[t]{2}{*}{12} & 0.039 & 0.070 & 0.168 & 0.120 & 0.232 & 0.101 & 0.089 & 0.057 & 0.048 & 0.031 & 0.028 & 0.017 \\
\hline & & 0.026 & 0.064 & 0.100 & 0.121 & 0.146 & 0.133 & 0.143 & 0.110 & 0.071 & 0.044 & 0.026 & 0.014 \\
\hline \multirow[t]{2}{*}{120} & \multirow[t]{2}{*}{8} & 0.030 & 0.119 & 0.310 & 0.208 & 0.090 & 0.119 & 0.094 & 0.030 & - & - & - & - \\
\hline & & 0.103 & 0.240 & 0.206 & 0.200 & 0.129 & 0.069 & 0.037 & 0.021 & - & - & - & - \\
\hline \multirow[t]{2}{*}{180} & \multirow[t]{2}{*}{6} & 0.190 & 0.230 & 0.190 & 0.160 & 0.130 & 0.100 & - & - & - & - & - & - \\
\hline & & 0.230 & 0.290 & 0.204 & 0.143 & 0.086 & 0.047 & - & - & - & - & - & - \\
\hline \multirow[t]{2}{*}{360} & \multirow[t]{2}{*}{6} & 0.290 & 0.200 & 0.160 & 0.120 & 0.140 & 0.090 & - & - & - & - & - & - \\
\hline & & 0.276 & 0.214 & 0.184 & 0.174 & 0.091 & 0.060 & & - & - & - & - & - \\
\hline
\end{tabular}

East Coast of Peninsular Malaysia

Southern Region of Sarawak

It can be seen that the temporal pattern is quite similar for 10 and 15-minutes duration, due to the nature of the short period of rainfall, but deviate as it reaches the 30, 60 and 120-minutes rainfall, as much as $23.2 \%$ of the total rainfall.

\section{CONCLUSION AND RECOMMENDATION}

The study has developed a set of temporal pattern for Southern Region of Sarawak, encompassing 7 basins from the region based on recommended steps and procedures from [1], [2], and [3]. It is concluded that the temporal rainfall pattern for the studied region is different from the pattern developed for East Coast of Peninsular Malaysia.

Thus, recommendation is made for future studies to develop a set of temporal rainfall pattern for Sabah and Sarawak for future reference. Notably, due to the heterogeneous elevation data selected for the rainfall stations, it is also recommended that future studies could classify the region based on its elevation data and the annual rainfall received.

\section{ACKNOWLEDGMENT}

The authors would like to acknowledge Universiti Malaysia Sarawak and Osaka Gas Foundation for International and Cultural Exchange (OGFICE) for the funding and support provided towards this project.

\section{REFERENCES}

[1] Rahman, A, S. M., Rahman, K., Khan, S., Shrestha, S. "A Windows-based Program to Derive Design Rainfall Temporal Patterns for Design Flood Estimation". Modeling and Simulation 2005: Modelling and Simulation Society of Australia and New Zealand Inc. 2005.

[2] Department of Irrigation and Drainage Malaysia. "Manual Saliran Mesra Alam Malaysia: Design Fundamentals". Malaysia, 2000, Vol (4).

[3] Department of Irrigation and Drainage Malaysia "Hydrological Procedure No.1: Estimation of the Design Rainstorm in Peninsular Malaysia (Revised and updated)". Malaysia. 1982.

[4] Bedient, P.B. and W.C. Huber, 'Hydrology and Floodplain Analysis', 3rd Ed. Prentice-Hall Publishing Co., Upper Saddle River, NJ. 2002.

[5] Institution of Engineers, Australia, 'Australian Rainfall and Runoff : A Guide to Flood Estimation' Eds Pilgrim, D.H., Barton, ACT. 1987.

[6] Kuan P.L. "Development of Temporal Rainfall Pattern for West Sarawak", Bachelor Thesis, Universiti Malaysia Sarawak, 2008.

[7] Anyie, J.K., 'Development of Temporal Rainfall Pattern for Sarawak', Bachelor Thesis, Universiti Malaysia Sarawak, 2009.

[8] Pilgrim, D. H., Cordery, I. and French, R. (). “Temporal Patterns of Design Rainfall for Sydney". Institution of Engineers, Australia, Civil Eng. Trans., Vol. CE11, 1969. No. 1, pp 9-14.

[9] Chuckwuna, G. O. and Schwab, G. O. (1983). Procedure for Developing Design Hyetographs for Small Watersheds. Transactions ASAE, 26(5), pp 1386-1389. 